\title{
RSP Revisitada Nenhuma reforma se mantém viva sem a pressão política
}

Edmur Arnaldo Chieregatto

Texto publicado na RSP, v. 113, n.1, nov./dez., 1985.

Escrito em 1985, o artigo de Edmur Arnaldo Chieregatto traz consigo debates importantes sobre o tema da reforma administrativa, assunto que ressurge com vigor no atual cenário político nacional. Chieregatto contrapõe às convencionais visões do processo de modernização uma proposta mais flexível, mais voltada para os mecanismos de sua implementação, para a participação democrática e para as políticas de governo em programas prioritários. $\mathrm{O}$ autor ressalta que mais uma vez se vivia um período de agitação e de expectativas em torno de uma necessária reforma administrativa no setor público. Todavia, momentos como esse não deveriam ser compreendidos como reação a um longo período de estagnação, mas sim, deveriam ser vistos como parte de um processo permanente. Utilizando-se de linguagem metafórica, para Chieregatto a reforma que se cogitava era como um rio de longos trechos surpreendido por cataratas, dando a enganosa impressão de que as águas que a antecediam estavam estagnadas. Para o autor, nenhum processo de reforma e modernização administrativa se manteria vivo sem pressão política capaz de exigir constantes e insistentes modificações. A pressão política por reforma seria, portanto, vital para sua dinamização. Embora originada nos altos escalões do governo, a reforma deveria estar lastreada nas demandas da sociedade, por meio de seus canais de representação. Em nova metáfora, Chieregatto ressalta que a grande corredeira nunca se deteve e nem se deterá. Ela poderá ter cavado seu próprio leito, com seu ritmo, o que pode não ter atendido às expectativas da sociedade brasileira como um todo. $\mathrm{Na}$ perspectiva do autor, porém, nada é absolutamente velho ou absolutamente novo. Nisso residem as esperanças de uma reforma mais democrática e realista.

\section{Apresentação}

O presente artigo não pretende aprofundar, seja doutrinária, seja metodologicamente, a questão da Reforma Administrativa brasileira. Seus objetivos são bastante limitados: uma contribuição a mais, nesse momento de ampla discussão da oportunidade e do direcionamento das mudanças que o Governo pretende 
imprimir na máquina administrativa federal. Esse esforço reformista não é novo, mas, ao contrário, marcado por ciclos que se repetem, nesse processo permanente.

Para melhor situá-lo, optamos por rever seus antecedentes mais imediatos - a Reforma Administrativa de 1967.

Procuramos, depois, contrapor à visão convencional do processo de modernização uma proposta alternativa, mais flexível, menos indexada na estrutura física da organização pública e nos seus sistemas, métodos e procedimentos, e mais voltada para a viabilização, mais democrática e comparticipada, das políticas de governo, expressas pelo conjunto dos seus programas prioritários.

As conclusões pareceram-nos óbvias: o objetivo estratégico da Reforma poderia ser a minimização dessa dualidade perversa da existência de um setor dinâmico e elitizado, representado pela Administração Indireta, e de um setor letárgico proletarizado, representado pela Administração Direta, para fazer da contribuição reequilibrada de ambos um instrumento de resgate do reconhecimento e da respeitabilidade social de que tanto se ressente a Administração no momento presente. Talvez assim, setor público e setor privado, cidadãos e servidores, reconciliados, pudessem, num regime democrático, corresponsabilizar-se pelo desenvolvimento da sociedade brasileira.

\section{Os ciclos se repetem}

Mais uma vez vivemos a agitação e a expectativa em torno de uma necessária e significativa reforma da Administração do setor público, no Brasil. A começar pela Administração Federal.

Aos menos avisados, pode parecer que, depois de períodos hibernais, o Governo e a Administração despertam e se dão conta da superação, desta, pela evolução social, e decidem, de vez, recuperar o tempo perdido, superar a desatualização, buscando a modernização, para devolver à Administração o papel de instrumento privilegiado do Estado, na sua função ampliada de promotor e ator central no processo de desenvolvimento econômico e social.

Sem falar da fase colonial e do período imperial, foi assim, também, ao início e ao final da já agora Velhíssima República, especialmente sob o ímpeto racionalizante da ditadura de Vargas, quando era preciso legitimar politicamente, por resultados da ação administrativa, um governo espúrio na sua origem.

Na fase de redemocratização e de desenvolvimentismo, o Estado avançou mais, e as instituições públicas se multiplicaram, desempenhando papel relevante no processo de desenvolvimento acelerado do País.

Mas a sociedade modernizava-se mais rapidamente, ainda que, sobretudo em alguns setores, a Administração representasse muito mais um freio do que um fator 
acelerador desse processo de mudança social. Por isso, a Velha República dos militares de 1964 enfrentou o mesmo problema de legitimação que a ditadura de Vargas enfrentara. A necessidade de resultados via intervenção do Estado, agora integrado como produtor ao modelo capitalista, exigia uma Administração mais eficiente e eficaz, através de instrumentos mais adequados as suas realizações no campo econômico e social. Mais do que isso, o próprio controle burocrático sobre a sociedade.

As profundas reformas institucionais acabaram por desnaturar o direito constitucional e o direito administrativo brasileiro, no período revolucionário, exigindo dos doutrinadores e publicistas brasileiros, comprometidos com o regime, verdadeiras acrobacias jurídicas. Para justificá-las, veio juntar-se a Reforma Administrativa de 1967, tendo no Decreto-Lei n. 200 seu ponto central, além de um conjunto de textos complementares e de aplicação, também importantes, ainda que menos lembrados.

Tanto quanto a reforma de Vargas, a dos generais de 1964, embora assumida por civis, caracterizou-se pelo autoritarismo e pela impositividade, no que era sincrética com a realidade daqueles dias. Com isso, não se pretende subtrair-lhes os créditos a que faz jus. Mas é preciso, agora com o recuo histórico, reavaliá-la no quadro sóciopolítico em que ela emergiu e prosperou.

A Administração não é um extrato dissonante da realidade social a que pertence. Pelo contrário, é dela uma amostra fiel e significativa. Os governos militares trataram-na e manipularam-na com o mesmo estilo com que trataram e manipularam a sociedade brasileira.

A Nova República também se escandaliza com o estado a que chegou a Administração do País. Não nos estamos referindo aos privilégios, aos desmandos e à corrupção, que isso não é privativo, ao longo da história administrativa brasileira, de nenhum período governamental em especial. Num diagnóstico, talvez ainda superficial e muito marcado pela compreensível paixão dos oprimidos de ontem, agora responsáveis, um pouco deslumbrados e amedrontados com a hidra que herdaram ao tomar o poder, a Administração é vista como algo caótico, indomável, incapaz, ineficiente, autofágica, que precisa ser reformada e modernizada.

Ora, ela nunca deixou de sê-lo, desde que aqui se implantou com os colonizadores, certamente de maneira não-satisfatória. Mas não-satisfatória para quem? Da mesma forma como podemos falar em planejamento de conservação, relativamente a um determinado modelo econômico e social, a Reforma Administrativa também poderá ter sido satisfatória para as elites detentoras do poder; menos satisfatórias ou absolutamente insatisfatórias para os segmentos sociais oprimidos e sem capacidade e espaço para articulação dos seus interesses, capazes de fazer deles instrumento de ruptura daquele equilíbrio dinâmico e instável de uma sociedade 
sob opressão. Faltou à Reforma espaço e articulação, do que padeceu também o planejamento, para torná-los revolucionários, promovendo a ruptura do modelo então vigente.

A modernização administrativa - e aqui pouco importa a distinção qualitativa em relação à Reforma, pois que esta pode, em tese, envolver retrocesso, seja ele institucional, estrutural ou procedimental do aparelho de Estado - é um processo permanente, como um rio de longos trechos remansosos, surpreendido, de repente, por corredeiras e cataratas, diante das quais o que lhe antecede e sucede mais parecem águas paradas.

A Reforma de que se cogita agora começa a se desvendar como uma dessas grandes corredeiras, o que nos leva à enganosa impressão de que tudo estava estagnado antes e nada haverá depois, por um largo período. Entretanto, o processo não se deteve, nem se deterá. Poderá ter cavado o seu próprio leito, com seu ritmo, o que pode não ter atendido às expectativas da sociedade brasileira como um todo. Nada, porém, é absolutamente velho, nem absolutamente novo.

Os estudos e diagnósticos que irão precedê-la certamente revelarão pela mão dos especialistas, ângulos inéditos, provavelmente até aqui insuspeitados, ou pelo menos pouco analisados. Com a reabertura política e o novo regime, reabre-se o ciclo de 1946 a 1964, agora com uma sociedade mais amadurecida e articulada. Nisso residem as esperanças de uma reforma mais democrática e realista.

\section{Os antecedentes imediatos: uma visão sumária da reforma administrativa de 1967}

Seria ocioso repetir aqui, descritivamente, os objetivos, o conteúdo e o processo da reforma administrativa de 1967 . Suas origens e sua exegese, até por aqueles que dela participaram mediata ou imediatamente, são de fácil acesso aos interessados. Mais importa, talvez, para marcar o contraste com uma proposta alternativa menos convencional, recuperar, criticamente, algumas das suas características.

Antes de qualquer coisa, é preciso ressaltar que nenhum processo de reforma e modernização administrativa se mantém vivo e aceso sem pressão política que o demande constante e insistentemente. A história recente revela que o DASP, a COSB, a CEPA, o ERA e a SEMOR ${ }^{1}$, como depositários da responsabilidade de impulsionadores do processo, a partir de certo momento, foram perdendo o poder de influenciação, o poder de intervenção e progressivamente, se apequenando,

\footnotetext{
1 Departamento de Administração do Serviço Público, Comissão de Simplificação Burocrática, Comissão de Estudos e Projetos Administrativos, Escritório da Reforma Administrativa, Secretaria de Modernização e Reforma.
} 
sustentados por disposições legais que lhes garantiam uma participação meramente formal, quase que restrita a alterações estruturais dos órgãos federais. Foi o que Ihes assegurou a existência e até a sobrevida. Coexistem hoje, com atribuições até superpostas, na melhor das hipóteses complementares, o Ministério da Administração, o Programa Nacional de Desburocratização e a Secretaria de Modernização e Reforma Administrativa - SEMOR.

Essa pressão política por reforma é vital para sua dinamização e agilização. Ela se origina e é mantida a partir dos altos escalões do Governo, mas deve estar lastreada na demanda constante e articulada da sociedade, através dos seus diferentes canais de representação. Sem isso, a reforma acaba sendo o desempenho burocrático de um conjunto de atribuições formais de diversos locais dentro do aparelho de Estado, tendo como fonte e destinatários os próprios órgãos e agentes públicos. Isso é extremamente empobrecedor e alienante no processo, pois marginaliza a sociedade como fonte suprema e destinatária última do próprio processo de modernização.

Recentemente, em março de 1985, a Fundação do Desenvolvimento Administrativo - FUNDAP, do Estado de São Paulo, promoveu um seminário sobre o Decreto-Lei no 200. Dele participando, Aluízio Loureiro Pinto teve ocasião de expressar interessantes considerações a propósito da Reforma de 1967.

A mais importante talvez seja a de que, a exemplo do que ocorreu em outras áreas, em especial na área econômica, a consciência da onipotência da qual se alimentava o Governo, em razão da sua origem e dos fatores de sua manutenção no poder, também empregou na área administrativa "o uso intensivo da força, impondo regras, normas, princípios, parâmetros em todos os níveis» (Loureiro Pinto, 1985, pp. 9- 21) com o que asseguraria um estatuto orgânico exemplar para a Administração Pública.

Não há como negar a pretensão válida de ordenamento, funcionalidade e moralização da gestão pública, objetivos do Decreto-Lei $n .^{\circ} 200.0$ reordenamento estrutural, a revalorização de princípios clássicos, como o planejamento, a descentralização e a delegação do controle constituíram-se em princípios básicos.

A ascensão e apogeu do planejamento coincidem com a época de maior vitalidade do Decreto-Lei no 200: a crença na suficiência criadora dos programas gerais, setoriais e regionais; até mesmo, por certo período, a visão estratégica do processo de desenvolvimento nacional, a formulação e a execução orçamentárias disciplinadas; por outro lado, a contabilidade pública e as licitações reordenadas.

Mas o que teria acontecido então para que, menos de 20 anos depois, clamássemos em uníssono contra o estado de coisas atual? Em outros termos: «Teria esse decreto as funções causais que Ihe são atribuídas? Que impactos foram 
substantivos? Que impactos foram adjetivos? O que é resultado de sua natureza intrinsecamente formal e o que defluiu da ambiência autoritária do processo modernizante, pós-64?» (LOUREIRO PINTO, 1985, p. 17).

A maioria dos especialistas concorda em que o «Decreto-Lei no 200 marca início efetivo do processo de racionalização da Administração Pública no Brasil. Os princípios do planejamento, da descentralização e do controle teriam fixado os parâmetros para o processo decisório nacional, a flexibilidade administrativa e a garantia do controle dos atos dos administradores, segundo a regra de que a autoridade vem acompanhada da responsabilidade» (LOUREIRO PINTO, 1985, p. 17).

Mas o discurso da racionalidade é bem anterior. Mais sistematicamente ele nasce com o DASP. O contexto da sociedade nacional e do aparelho de Estado era outro, por isso a racionalidade era mais adjetiva do que substantiva.

De acordo com essa ideologia racionalizante, caberia, como coube de fato até meados do Governo Geisel, papel relevante ao planejamento. Aos poucos seu discurso foi perdendo substância - conseqüência da sua perda de status político no seio do Governo - , quando Simonsen assume, no Ministério da Fazenda, o comando da economia brasileira, já em crise. A curta passagem do mesmo Simonsen, no Governo Figueiredo, pela Secretaria de Planejamento da Presidência, marginaliza não só a doutrina como os próprios instrumentos de ação do planejamento, cujos códigos sua equipe não dominava.

A Secretaria de Modernização e Reforma Administrativa, órgão central de um sistema de fato de reforma administrativa, inserida na órbita da SEPLAN-PR, aceita e contribui decisivamente para a emergência e relevância política do Programa Nacional de Desburocratização, privilegiado com o comando competente do Ministro Beltrão.

Esse é o primeiro momento decisivo para a perda de consistência e vitalidade do processo da Reforma Administrativa. O que era gênero, passa a ser espécie. A desburocratização, mera dimensão de um processo mais amplo de reforma e modernização, passa a ser gênero, da qual estas se tornam mero instrumento supridor de recursos financeiros e de mão-de-obra.

O segundo momento decisivo é a ascensão de Delfim Netto ao comando do planejamento. E a «pá de cal» não só para o planejamento, enquanto ideologia, método e instrumentos, sistema e estrutura, como em especial para a reforma administrativa, mal posicionada junto a uma elite de economistas pouco sensíveis à variável organizacional lato sensu.

Isso também não era inteiramente novo: em geral, o perfil do economista não o induz a colocar entre as variáveis das suas matrizes de viabilidade econômica, de custobenefício, indicadores da capacidade operacional da máquina administrativa. Daí a 
impressão de que programas e projetos são auto-executáveis, independentemente do grau de eficiência e eficácia do aparelho de Estado.

O planejamento estratégico ficou submerso diante dos instrumentos táticos, próprios da área ou da visão fazendária da economia. A área organizacional sobrou como apêndice incômodo; apenas reforço de um inquestionável e ostensivo núcleo de poder dentro do Governo.

Nem por isso a Administração deixou de modificar-se e evoluir: agravaramse a centralização, o formalismo, a simetria, mais como conseqüência do estilo já decadente do Governo. Só que a função de modernização e reforma deixou de comandar esse processo. Ele se desenvolveu com ritmo próprio, ao sabor de interesses variados.

Mas isso não seria o pior. Naquele momento, como dissemos, tornou-se patente a falência do planejamento como instrumento por excelência da modernização administrativa, desde que já se questionava "a correlação entre a ideação do planejamento e a qualidade e racionalidade das decisões tomadas» (LoUREIRo PINTO, 1985, p. 18).

Basta confrontar a evolução do posicionamento de Delfim Netto em relação ao planejamento, para compreender o grau de desprestígio a que este foi submetido.

Como professor de Teoria do Planejamento, assim se definia na apresentação do seu livro «Planejamento para o Desenvolvimento Econômico»:

"As críticas acerbas que tem sofrido, algumas vezes, o tipo de planejamento a que estamos nos referindo têm duas origens distintas, mas claramente discerníveis. De um lado, as classes conservadoras têm uma compreensão muito inadequada do processo de desenvolvimento econômico, pensando-o basicamente em termos quantitativos e atribuindo valor mítico ao mercado, o que as leva a rejeitarem o planejamento por inútil; de outro as classes revolucionárias, vendo nele um instrumento eficiente das sociedades abertas para realizarem os ideais do bemestar social, combatem-no por claras razões de ordem tática.

Para que o sistema de preços possa funcionar adequadamente, portanto, impõese que as modificações estruturais mais importantes sejam previstas e superadas antes de se tornarem um fator impeditivo da aceleração do desenvolvimento econômico. Este é o objetivo básico do planejamento.

Há um argumento que nos parece irrespondível. É ilusão pensar que existe a alternativa planejar ou não planejar, pois a única alternativa que existe, na realidade, é planejar bem ou planejar mal. Uma administração federal, estadual ou municipal ou mesmo privada, não deixa de planejar simplesmente porque não registrou de forma consciente as tarefas que terá de realizar no futuro. De uma forma ou de 
outra, o seu comportamento no presente condiciona a maneira pela qual ela terá de enfrentar os problemas do futuro, o que significa que a ação presente determina em grande parte a sua ação futura.

Sem a formulação de um programa, essa administração tem as suas opções consideravelmente diminuídas, pode provocar sérios desperdícios dos recursos escassos para o desenvolvimento. A vantagem de conscientizar o programa futuro reside justamente na possibilidade da escolha, das alternativas mais adequadas para a consecução dos fins almejados» (DELFIM NeTto 1966, pp. IV, VI e VII).

Como Ministro-Chefe da Secretaria de Planejamento da Presidência da República, sua postura viria a ser diametralmente oposta, quase chocante para o titular da área. Talvez apenas absorvida pelo poder real de que era ele detentor no seio do Governo.

«... No Brasil não há centralização nenhuma. No Brasil há sequer planejamento. De forma que ele não pode ser centralizado. O que há são algumas linhas de política econômica em que se procura orientar os vários setores a trabalharem naquela determinada direção... Eu estava começando a minha vida e o Adhemar de Barros decidiu fazer um planejamento. Eu fiquei curioso e perguntei: 'Mas, Dr. Adhemar, por que o Senhor vai fazer um planejamento?' E ele me respondeu: Ih, rapaz, porque o primeiro trouxa que passa aqui eu dou o livro pra ele. E fica todo o mundo convencido de que tudo está planejado'... Nós chegamos a ter, em 1964, não sei, cinco planejamentos em execução ao mesmo tempo. Necessariamente, eles não têm nada que ver com a realidade, mesmo. Eu até suspeito que o Terceiro Plano, que não tem nenhum enunciado concreto, vai ter mais coisas que ver com a realidade do que todos os outros, simplesmente porque ele enuncia as políticas, ele enuncia os mecanismos para induzir as pessoas a se comportarem desta ou daquela forma...»

E concluía o Ministro-Chefe da Secretaria de Planejamento da Presidência da República:

«... O planejamento é uma prática muito pouco eficaz... Isto porque, no planejamento, o que é importante não é o planejamento físico. O importante é o planejamento dos preços, isto é, como se vai induzir as pessoas a fazerem exatamente o que elas têm que fazer... A planificação, quando tem muita eficácia, é um sistema eficaz de cópia, mas jamais um sistema de criação... Para a Economia como um todo, o planejamento é uma ilusão ...» (DELFIM NETTo, 1980, pp. 39-42).

Esse réquiem ao planejamento foi a herança deposta nas mãos do Ministro Sayad, na Nova República. E aí continuam enquistadas a modernização e a reforma administrativa, já agora, aparentemente, sob o comando explícito do Ministro da Administração, coadjuvado pelo Ministro Extraordinário da Desburocratização. 
Uma espécie de Santíssima Trindade às voltas com o desafio de uma nova grande Reforma, prometida à sociedade brasileira.

Relatando outros posicionamentos manifestados no Seminário sobre o Decreto-Lei no 200, promovido pela FUNDAP, Loureiro Pinto sumaria: «... Jorge Hori examina com propriedade o contexto autoritário pré e pós-decreto, dentro do qual inúmeras e sérias distorções foram criadas. Dos efeitos perversos por ele detectados, destacam-se a concentração de recursos da União, a macromelia dos serviços paraestatais públicos, em todos os níveis, gerando custos elevados que neutralizaram seus objetivos principais, bem como as tentações corruptivas pela adoção de normas que, apesar de legais, não são éticas.»

A centralização também é vista como uma estratégia de controle governamental, bem "pensada», para Belmiro Castor. Seus efeitos, entretanto, longe de colimar tal objetivo, tornaram o Decreto disfuncional por ter ensejado uma metástase burocrática incontrolável em todos os níveis de Governo. Na realidade, o inchamento do aparato burocrático gerou quatro «fascínios», a saber:

- A crença na eficiência econômica setorial;

- A uniformidade, expressa nas tendências ao formalismo no centro e a simetria no aparato organizacional dos Estados e Municípios;

- O fetichismo da escala; e

- A mesmerização trazida pela crença da modernidade.

Embora a leitura fria do decreto não obvie tais interpretações, não resta dúvida tratar-se de um "capo lavoro» das elites modernizantes, expressando-se em uma das inúmeras tentativas de regular a ambiência política (LOUREIRO PINTO, 1985 pp. 18-19).

\section{A visão convencional do processo de reforma administrativa}

Tradicionalmente, a Reforma Administrativa tem sido vista como o esforço do aperfeiçoamento da máquina administrativa, objetivando, mediante sua constante racionalização, o aumento da sua eficiência e eficácia. Esse posicionamento, ainda que amplo e genérico, nos parece insuficiente.

O conceito amplo da reforma administrativa pode consistir em vê-la, na órbita federal, como o processo de mudança organizacional planejada das Administrações Direta e Descentralizada, aí incluídas suas relações com as Administrações Estaduais e Municipais, com as diferentes instituições representativas da sociedade civil e, em última instância, com o próprio cidadão.

Dessa ótica, o processo é bem mais abrangente do que sua conformação aos estreitos limites da Administração Federal propriamente dita. De qualquer forma, seu objetivo seria o de aperfeiçoá-la, como instrumento de realização das políticas públicas. 
O objeto desse processo pode ou deve alcançar, isolada ou conjugadamente, além das quatro dimensões tradicionais: a institucional, a estrutural, a funcional ou operacional, e a comportamental, uma quinta dimensão, aquela das relações do aparelho de Estado com a sua variada clientela específica.

A intervenção modernizadora nessas cinco dimensões, cujos conteúdos serão, a seguir, mais bem explicitados, define a natureza multidisciplinar do processo de reforma administrativa, o que exige uma capacidade de formulação e de coordenação integrada e integradora. Só assim se poderá evitar o risco de tratar a reforma como um conjunto de compartimentos estanques, sujeitos, portanto, a concepções e metodologias individualizadas, redundando num todo heterogêneo e sem organicidade.

Os limites postos ao processo de reforma devem ser cuidadosamente analisados, para evitar conformá-lo, num plano ideal, muito além das possibilidades reais de sua efetiva implantação. Esses limites são, essencialmente, de natureza cultural, política, técnica e financeira.

A força de identificar o processo e reforma ou modernização administrativa com o aumento da racionalidade da burocracia estatal, acaba-se por dar exagerada proeminência à sua dimensão técnica. Entregue a especialistas das diferentes técnicas da área organizacional, esse equívoco é quase natural.

Entretanto, o processo da reforma é essencialmente político, e, secundariamente, técnico. Nessas condições, constituem seus limites básicos aqueles decorrentes do estágio cultural e político da sociedade brasileira, da qual o setor público, enquanto organização social, é uma amostra significativa. A tecnologia da mudança, ainda que relevante, é uma questão apenas secundária.

Por outro lado, preocupados com os resultados finais, delegada aos especialistas das suas diferentes dimensões e conteúdos a proposição das sugestões racionalizantes, desconhecem os responsáveis finais pelas decisões de implantação das propostas de mudança de seu custo final, em termos financeiros. Quando eles se evidenciam, revela-se a impossibilidade de sua implementação global, e uma saída infeliz tem sido a de, por razões ou interesses pouco claros, mudar aqui e ali, transformando o plano geral da mudança numa colcha de retalhos, sem muita coerência e logicidade.

Essa observação não inibe a validade de uma estratégia de implantação seletiva e gradual. Mas isso não se confunde com intervenções isoladas e aleatórias, diante da escassez de recursos para enfrentar o processo de mudança como um todo harmônico e integrado.

Algumas premissas, mesmo a partir dessa visão convencional do processo de reforma administrativa, devem servir-Ihe de balizamento. De forma não-exaustiva, parece-nos importante citar: 
- A Reforma é instrumental para o aperfeiçoamento do desempenho das funções do Estado ${ }^{2}$, tendo como foco o cidadão ou as instituições destinatárias da sua ação, não se caracterizando, portanto, por ser uma finalidade em si mesma, para consumo intra-organizacional, tendo como foco o agente público, como seu destinatário final.

- A Administração Federal, objeto imediato da Reforma, não pode ser considerada de forma isolada, dentro do setor público nacional.

Ainda que a nova Constituição possa melhor caracterizar a Federação brasileira, a interpenetração dos três níveis de governo e suas respectivas administrações, na especialíssima federação do País de nossos dias, recomenda tomar em consideração que a exclusiva modernização da Administração Federal não se traduzirá em ganhos significativos se não for acompanhada de melhoria da eficiência, eficácia e efetividade das Administrações Estaduais e Municipais.

O estágio destas é, por assim dizer, limite seríssimo ao alcance da Reforma Federal. Este é um dado de realidade que, certamente, não escapará aos conhecedores dos meandros das relações intergovernamentais no Brasil, sobretudo diante de objetivos mais sérios de descentralização administrativa.

Trataremos mais aprofundadamente dessa relevante questão, quando do exame de uma proposta de agenda para a nova Reforma.

- A direção a ser imprimida ao processo da Reforma Administrativa será reveladora do posicionamento do agente público, em face do seu duplo papel de inovador e integrador social.

Será reveladora, ainda, da concepção que se faça das organizações públicas enquanto provedoras do interesse público, o que, em última instância, as legitima perante a sociedade, pelo que têm elas definida responsabilidade social a orientarIhes a busca da eficácia organizacional.

- A melhor reforma não é aquela que a melhor inteligência dos seus agentes é capaz de produzir, mas aquela cuja habilidade política dos dirigentes seja capaz de tornar aceita e assumida pelos seus destinatários, sejam eles agentes públicos, instituições privadas, ou os próprios cidadãos.

Trata-se, portanto, prioritariamente, mais de competência e estratégia política de fazê-la passar e sustentar-se, do que habilidade técnica de formulá-la.

\footnotetext{
2 Do ponto de vista ideal, a definição dessas funções do Estado, revestida sempre de um caráter dinâmico, deveria resultar de um processo tão democrático e participativo quanto possível.
} 
As dimensões da Reforma Administrativa já foram anteriormente explicitadas. Conviria aqui apontar os principais conteúdos de cada uma daquelas cinco dimensões.

- A nível institucional, inseparável do ordenamento constitucional - e reside aqui um risco de a Reforma anteceder à nova Constituição - , constituem-se em objetos naturais de estudo, entre outros: a clara delimitação do campo de atuação das Administrações Federal, Estadual e Municipal, para desumir dele a competência, o poder e os institutos pertinentes à esfera federal, bem como as formas de articulação com a sociedade civil e os demais níveis de governo e suas administrações; além disso, a revisão de toda legislação pertinente ao direito administrativo.

- A nível estrutural, são objetos privilegiados de estudo: o desenho organizacional (funcionalidade e superposições) da macro e micro-organização das Administrações Direta e Indireta; a revisão estrutural e das atribuições dos principais sistemas que compõem a Administração Federal, e em casos especiais certos sistemas nacionais.

Merece amplo destaque, nesse nível, a questão do Sistema de Pessoal Civil da União. Questão essa sempre objeto de tratamento formal e, num plano ideal, quase sempre em contraste com a realidade das práticas político-administrativas correntes no País. Concurso, mérito, carreira, classificação de cargos, treinamento, são temas eternos e ainda não satisfatoriamente resolvidos, na busca da profissionalização da função pública brasileira, ao longo de quase cinco décadas.

O tratamento meramente jurídico dessas questões, inclusive a do novo Estatuto, será sempre insuficiente, já que subjacente a ele está a concepção política que se faz do Estado e dos seus agentes.

- A nível funcional ou operacional, coloca-se a questão dos princípios básicos da ação administrativa federal. Nesse terreno, reconheça-se, avançou largamente a Reforma de 1967, com as críticas já aqui apontadas. A experiência desses quase 20 anos de prática será extremamente útil, não só para a sua revisão, como, especialmente, para a inserção de outros princípios ou a redefinição dos antigos.

No domínio da tecnologia administrativa e, em especial, a gerencial, reside um dos maiores desafios à nova Reforma. Não é apenas uma questão de métodos e procedimentos. Ela vai mais longe. Os melhores analistas da eficácia da ação administrativa do Estado são concordes em assinalar a baixa capacidade gerencial do setor público como grande responsável pelos baixos níveis de utilização dos já escassos recursos públicos, o que se torna crítico, especialmente, num período prolongado de agravada crise econômico-financeira do País. 
- A nível comportamental situa-se, a nosso entender, o maior problema a ser enfrentado pela Reforma. Aqui a questão não é técnica senão adjetivamente. Ela é substantivamente cultural. E nesse terreno não há milagres. Há necessidade de compatibilizar os valores gerais, próprios da sociedade brasileira, e os do setor público, em particular, o estágio cultural deles decorrente, com a filosofia e o estilo administrativo pretendido pela Nova República. Mas a definição deste não pode ser arbitrária, sob pena de novamente termos uma reforma formal e inaplicável.

O discurso da profissionalização pela capacitação e valorização do servidor público, em especial quanto à Administração Direta, está gasto pelo tempo e pela limitação dos seus resultados. Vencer a alienação decorrente de uma inegável proletarização da Administração Direta é batalha tão difícil quanto a de superar a alienação oposta, aquela do setor indireto, que tanto tem comprometido o sentido social da intervenção do Estado, via suas entidades descentralizadas.

- Finalmente, a nível das relações da Administração com sua clientela específica, é preciso ter em conta a passagem de um sistema autoritário e auto-suficiente para um sistema mais democrático, criando-se espaços e canais administrativos para a manifestação dos interesses dos diferentes segmentos da sociedade, cujos conflitos naturais cabe ao Estado administrar, através do seu aparelho burocrático, igualmente democratizado.Todavia, por não serem novas, as questões aqui levantadas, até por tradição, correm o sério risco de se verem tratadas pela forma convencional das reformas anteriores. Concordamos por essa razão com Loureiro Pinto, quando este adverte, lembrando o Decreto-Lei no 200:

«Na visão multifacetada do Decreto, as diversas análises conduzem a uma indagação: se tal legislação reflete matrizes culturais autoritárias, atenuadas por breves intervalos de desenfatização da modernização administrativa, e se tais matrizes não parecem em vias de anulação, pode-se prever preservação ou repetição em tempos próximos?

«Infelizmente - prossegue o autor - a resposta parece ser afirmativa. Historicamente, a tecnificação da Administração Pública brasileira tem-se acentuado, sem hiatos, desde a Revolução de 30.

«Na área federal, a criação de poderosos estamentos tecnocráticos nas atividades fiscais e de gestão de complexos mecanismos nos setores energéticos, de saneamento básico e previdenciário apontam no sentido de maior tecnificação. Nos Estados e Municípios, a simetria de modelos e os requisitos de funcionamento sincrônicos desses setores instilou pressões também tecnificantes, tudo agora estimulado pela difusão da informática.

«Para o setor privado, a legislação corporificada no Decreto-Lei n. 200 introduziu certeza de relações com o Governo, produzindo interesses fortes na sua preservação. 
«O setor público, representado pelas estatais, seguramente preferirá ver o Decreto revogado, pois tolhe sua flexibilidade.

«A criação de um verdadeiro sistema democrático, descentralizado, tornaria, entretanto, tal legislação desnecessária, já que se assenta em parâmetros centralizadores e uniformizadores. Uma verdadeira federação daria a cada um dos níveis de Governo normas próprias e peculiares. Resta saber como os saudosistas da tradicional cultura político-administrativa reagiriam diante de tanta liberalidade política.» (LOUREIRO PINTO, 1985, pp. 20- 21).

\section{Uma proposta alternativa para a nova reforma administrativa}

É precisamente a busca de um modelo de atuação mais democrática e conseqüente da burocracia estatal, como pressuposto, que nos anima na especulação de uma proposta alternativa para o processo da nova Reforma, atualmente em marcha.

Partimos do compromisso político do Governo com a comunidade: ser agente de mudanças. De mudanças significativas de natureza econômica e social. Esforço apoiado em sacrifícios mútuos, mediante uma intervenção do Estado mais justa e eficaz, sem desperdícios, valorizando o que é essencial e desprezando o meramente útil ou supérfluo. A ação administrativa é a forma natural dessa intervenção.

Os governos se sucedem nas promessas, propostas e ações, vinculadas a um conjunto de políticas públicas. Todos aqueles que assumem postos estratégicos para a realização daquelas intervenções acabam, de certa forma, frustrados diante dos resultados limitados «do que Ihes foi possível» realizar. Mais, acabam angustiados diante do desencanto e da revolta da comunidade, acalentada no seu sonho fantástico de mudanças radicais, de curto e curtíssimo prazos. Explicações, justificativas e até acusações se avolumam, compondo um quadro complexo quanto à real capacidade da Administração para a operacionalização daquelas políticas.

Há, por assim dizer, uma distância profunda «entre o nível da formulação política e aquele da realização institucional, tanto no campo do conhecimento, quanto no da prática administrativa» (GARCIA, 1985 pp. 56-57). Essa evidência nos remete a um questionamento mais sério, seja sobre a adequação e efetividade das políticas formuladas - si et in quantum - seja sobre a capacidade, propriamente dita, de sua implementação pela Administração.

Considere-se, por um lado, a dificuldade real de auto-análise típica da Administração e própria dos governos, bem como, por outro lado, a deficiência da análise externa das realizações governamentais, pelos óbices e sonegações já tradicionais, e ter-se-á um quadro extremamente simplista de responsabilização generalizada da burocracia pelo baixo índice de realização dos governos. A isso 
contribuem as reconhecidas disfunções próprias da burocracia, sobretudo a estatal.

Uma das causas mais freqüentemente apontadas como responsável pela insuficiência da ação programática do Governo é a centralização e formalização excessivas, decorrentes do próprio modelo burocrático de organização e funcionamento da Administração Pública. Modelo esse largamente autoritário, de difícil questionamento e mudança.

Resulta que as sucessivas tentativas de reforma objetivaram, em última instância, correções e aperfeiçoamentos desse mesmo modelo. Esses fatores, tirante a natural evolução da Administração no acompanhamento da própria evolução da sociedade brasileira, que se foi modernizando, acabaram-se revelando insuficientes no seu aspecto mais importante, ou seja, no aumento do índice de implementação das políticas públicas.

Daí a idéia de orientar a nova Reforma por um caminho mais pragmático e comprometido com as intervenções prioritárias do Estado.

Como já ressaltamos, o pressuposto para a Reforma, no momento histórico por que passamos, é sua orientação para a busca, o desenvolvimento e a difusão de um modelo mais democrático para a organização administrativa do Estado. Isso implica não desconhecer a dimensão política subjacente a essa ação administrativa.

Implica, também, reconhecer que a realização em níveis mais elevados dos objetivos das políticas públicas não se reduz à estrita ação da burocracia de Estado - como se tudo dependesse, exclusivamente, dela - mas da sua capacidade de articulação com outros segmentos societais, mediante a redefinição de papéis, cristalizados ao longo da história.

Uma nova filosofia de ação, um novo estilo administrativo, uma nova organização do aparelho de Estado são necessários; mas, ainda assim, insuficientes para um processo administrativo mais dinâmico e de responsabilidade social mais ampla. É preciso dar-lhe complementaridade com a atuação institucional do setor privado e, ao final da escala, com a do próprio cidadão. Talvez, para tanto, tenhamos que desmistificar a idéia de que a contribuição da sociedade para com a administração da coisa pública se esgota na exação tributária. Tudo o mais seria por conta do Estado, inclusive o controle de suas próprias ações e resultados dela.

A nova Reforma deve abrir perspectivas, através da organização pública, para uma atitude menos passiva da sociedade, a quem não resta outra alternativa senão aquela, a posteriori, de punir os maus governos pela derrota nas urnas, quando isso lhes é permitido, num regime democrático.

Modernizar a Administração, fazendo dela um instrumento propulsor e não um freio ao desenvolvimento da sociedade é um desafio eterno. E também, por 
vezes, uma proposição oportunista, enganosa e piegas, quando formulada a partir de premissas restritivas, levianas e demagógicas. A Nova República, comprometida com uma nova postura, não pode repetir um processo convencional de reforma tecnocrática da Administração desvinculado de um comprometimento com realizações concretas.

A nova Reforma, a quem se assina esse desafio, não pode se permitir uma visão estreita capaz de colocar, como sempre, o problema ao nível da operação mecânica dos sistemas administrativos, da formação e desenvolvimento dos recursos humanos como um objetivo em si mesmo, e a reformulação estrutural, como arranjos racionais ou compromissos para o compartilhamento do poder.

Certamente nada disso é novo. Mas não custa tentar reequacionar o problema.

Uma nova postura importa uma visão menos feudal, departamentalizada, legalista, mecanicista, enfim menos burocrática da Administração.

No já referido Seminário sobre o Decreto-Lei no 200, promovido pela DUNDAP, Ramon Garcia (1985, pp. 55-82) teve ocasião de chamar a atenção para a estruturação de redes, como forma alternativa de organização e gestão. Nele nos inspiramos em largas passagens para este posicionamento.

Dentro de um contexto mais democrático e participativo, a Administração, independentemente de sua configuração formal e dos seus sistemas de apoio, pode ser vista como um conjunto de redes, com diversos elos de interligação, em diferentes níveis, onde ressalta um certo grau de flexibilidade dos chamados grupos informais, canais privilegiados no processo de formação das decisões públicas.

As principais políticas de governo, resultantes da agenda política e da articulação dos partícipes de sua discussão, emergentes interna ou externamente à Administração- até mesmo de forma combinada - se expressam através de um conjunto de programas prioritários, nos diferentes setores de atuação do Estado, com atores ocupantes de variadas posições dentro de uma macrorrede. Esses atores estão dispersos seja pela Administração Federal (direta ou indireta) exclusivamente, ou associados a outros nas esferas estadual e municipal, em programas verticalizantes, ou, ainda, associados a agentes do setor privado.

Essa proposta alternativa seria partir da identificação dos principais programas para a realização das diferentes políticas públicas; a identificação dos principais gestores desses programas, suas vinculações institucionais, seu posicionamento nessa rede de interrelações e interdependência; a formação real e ideal dessa rede, com eventual incorporação a ela de outros segmentos pertinentes, mas formalmente dissociados dela para, a partir disso, quase como um processo de tomografia administrativa, encontrar os nós, os pontos de estrangulamento da ação implícita para a realização daqueles programas. 
Como conseqüência, chegaríamos a necessidades de intervenção institucional, estrutural, funcional, comportamental e de relacionamento com a clientela ou público-alvo desses programas. Como se percebe a proposta é de um procedimento inverso do tradicional.

Definidas as áreas de resultado na consecução das políticas públicas e obtida a avaliação da capacidade operativa dessas redes nelas envolvidas, a Reforma se orientaria, pragmaticamente, por esses resultados. Isso evitaria investimentos humanos e financeiros em correções tecnicamente até corretas em setores pouco significativos ou alienados da ação prioritária do Governo que, estimulados pela onda reformista, até por um compreensível efeito-demonstração, detonariam, no seu âmbito específico, processos de reforma como um fim em si mesmo.

Essa nova estratégia asseguraria economicidade e objetividade ao processo de reforma e, mediante a identificação clara pela comunidade da objetividade desse processo, manteria articulada, agora dentro de um regime democrático de canais de representação desbloqueados, uma pressão política externa constante pelo prosseguimento e aprofundamento da reforma, incapaz de ser contida pelo natural acomodamento congênito à Administração Pública. O controle por resultados seria de domínio público, aferido mais facilmente, liberado do controle estrito dos gabinetes oficiais, como se verifica quando a reforma é «propriedade exclusiva da própria Administração», em última instância objeto dela.

Adaptada do texto de Ramon Garcia (1985, pp. 62-64), apontamos a seguir o que nos parece poderia ser a orientação central da Reforma - visando à adequação do aparelho de Estado para a consecução das políticas públicas:

- o aperfeiçoamento da integração institucional, através da «articulação de elementos isolados de um mesmo sistema ou de sistemas diferentes», o que sempre acaba sendo revelado pela emergência de problemas decorrentes da rigidez e fragmentação estrutural daqueles sistemas;

- o fomento da intermediação institucional, assumindo-o, estimulando-o ou dele participando, promovendo «a colbcăção em contato de pessoas, necessidades, ou interesses legítimos que se encontram separados por desconhecimento ou barreiras burocráticas desnecessárias»;

- o favorecimento da articulação de grupos informais, abrangendo «um conjunto de atividades que se expressam através de redes pessoais e informais de relacionamento. Quaisquer grupos de interesses, por exemplo, reúnem em bases informais pessoais com várias qualificações profissionais e que podem pertencer a diferentes setores de uma organização ou distintas instituições»;

- o estímulo à coordenação de projetos, mediante a ação mais democrática de grupos de trabalho, com a finalidade de «provocar mudanças de curso de uma 
organização ou, ainda, promover maior integração entre instituições diferentes ou propiciar apoio institucional a projetos de caráter interorganizacional»;

- a capacitação no gerenciamento de rede, instrumentando uma massa crítica de agentes para «as necessidades operativas da rede, assegurando o fluxo de decisões, de informações e de recursos materiais indispensáveis ao seu pleno funcionamento»;

- a facilitação de rede, mediante a identificação e «remoção de dificuldades ou obstáculos, devidos à rigidez burocrática. Em um contexto regional ou local, assume um caráter estratégico, pois procura realizar no plano local diretrizes políticas de caráter mais geral. Abrange um conjunto de atividades, tais como: expedição e acompanhamento; consultoria e assistência técnica; orientação e intermediação; treinamento de quadros locais;

- a edificação institucional, orientando as ações da Reforma para o «aperfeiçoamento de redes ou de instituições». O «edificador» procurará mostrar que as ações estratégicas de uma rede (ou organização) só teriam sentido quando contribuem para a afirmação de uma dada «identidade organizacional», que se obtém quando se aprofundam as questões relativas aos valores normativos e ao sentido de missão da instituição».

- a negociação de rede, através da qual a Reforma objetivaria, através de mecanismos especiais, "resolver não só os conflitos internos de interesses, entre unidades e indivíduos, como também procurará proteger os interesses legítimos de unidades ou indivíduos das exigências totalitárias e coercitivas dos grandes sistemas organizados».

Enfim, lastreia-se nessa visão a proposta alternativa para o processo da nova Reforma. Com isso se pretende assegurar uma visão utilitarista do processo, mais adequada às restrições do País a um processo amplo e generalizado, mais demorado e custoso.

\subsection{Macrotemas para a reforma administrativa}

Dentro desse espírito, entretanto, é possível vislumbrar que o aperfeiçoamento das redes de execução dos programas prioritários de governo terá rebatimentos necessários num conjunto de problemas ou aspectos já tradicionais na Administração Pública.

Há, por assim dizer, um certo número de macrotemas que a Reforma terá de abordar, inevitavelmente.

\subsubsection{A repartição de tarefas/funções entre a União, os Estados e os Municípios}

Trata-se de matéria de fulcro constitucional, mas de clara repercussão na esfera estrutural e funcional das respectivas administrações dos três níveis de governo.

Seria de todo conveniente que a Reforma avançasse na descaracterização da simetria hoje existente, supondo-se o Brasil, um país homogêneo. Conviria 
estabelecer uma tipologia básica de Estados e Municípios, como parâmetro para a definição das responsabilidades próprias, exclusivas ou concorrentes, de cada um daqueles três níveis administrativos.

\subsubsection{A Descentralização Administrativa}

Este se apresenta como o tema predileto da Nova República. A Reforma, portanto, deverá dispensar-Ihe cuidadosa atenção, examinando-lhe os desdobramentos possíveis, que compreendem, pelo menos, como aspectos principais:

- A descentralização intergovernamental, entendida como a transferência de funções, no todo ou em parte, para os outros níveis de governo. Trata-se da estadualização e municipalização de ações federais. Este objetivo, de largo alcance político e administrativo, depende da efetiva capacidade dos Estados e Municípios em operacionalizar satisfatoriamente as atribuições transferidas. Dentro da heterogeneidade administrativa brasileira, essa descentralização não pode ser simétrica, nem irreal. Aportes financeiros suplementares aos Estados e Municípios não suprem, de pronto, a fragilidade administrativa desses níveis, salvo raríssimas exceções.

- A desconcentração intragovernamental, concebida como a delegação de atribuições aos níveis periféricos da administração federal, em especial aos segmentos dela que representam interfaces com as administrações estaduais.

- A descentralização intragovernamental, com passagem de atribuições de órgãos da Administração Direta para entidades da Administração Indireta, já existentes ou a serem criadas. Nada impede que a Reforma, reexaminando a descentralização existente, corrija distorções, revertendo aqui e ali excessos injustificados de descentralização.

- A regionalização da ação administrativa federal, para dar conseqüência ao planejamento regional, através das Superintendências de Desenvolvimento Regional e de outros órgãos, nos setores de execução direta pela União.

- A administração dos programas federais de execução pelos Estados, mediante convênio.

A estratégia adotada pela União de centralizar recursos e descentralizar a execução via Estados ou Municípios, redundou na grande importância da chamada administração convenial. Hoje, grande parte dos Estados mais carentes de recursos próprios somente pode realizar parte da manutenção de serviços já existentes ou investimentos para a sua ampliação através de recursos obtidos via programas federais setoriais. 
As administrações estaduais desempenham, assim, dois conjuntos de ações: um decorrente das ações próprias do Estado; outro decorrente de programas de interesse federal. Não é difícil compreender que grande parte do esforço de modernização da Administração Federal se perderia na hipótese, muito provável, de suas políticas e programas ficarem sob a responsabilidade executória de máquinas administrativas estaduais obsoletas e ineficazes.

Dentro dessa alternativa de a Reforma centrar-se nas redes, é fundamental a identificação dos elos com as Administrações estaduais, para que os segmentos destas, envolvidos na execução dos programas federais, sejam de imediato, objeto também de modernização.

\subsection{A revisão dos grandes sistemas administrativos}

À época da Reforma de 1967 imperava na teoria administrativa um certo deslumbramento quanto à forma sistêmica de organização. Criaram-se, ao nível federal, pesados sistemas administrativos. Depois de tantos anos de maturação, conviria analisar se teriam eles conseguido superar a fase de definição formal para a de um desempenho adequado, assegurada pelo relacionamento harmônico e orgânico dos seus órgãos centrais, com os setoriais e seccionais. Não é demais salientar que a forma sistêmica de organização exige além da competência técnica para a definição das funções dos seus componentes, uma vontade política de abrir mão de parte do poder, em favor do órgão central na sua ação normativa. Em contrapartida, esse mesmo órgão central não pode exacerbar sua autoridade, hipertrofiando-se à custa da minimização da ação setorial e seccional.

4.3. As Empresas Públicas devem constituir um capítulo especial na nova Reforma. Justificabilidade, qualidade de desempenho em face da sua missão social, formatação e dimensões organizacionais, superposição com outros órgãos e entidades são alguns dos critérios que deverão nortear-lhes o exame e eventual intervenção por parte da Reforma.

Cuidado especial deve merecer o relacionamento entre as grandes empresas públicas federais e as suas subsidiárias estaduais, praticamente manietadas diante do grau de centralização exercido pelas «holdings» nacionais.

4.4. Os organismos de proteção e controle pela comunidade, idéia longamente amadurecida e coberta por iniciativas isoladas, seja a nível federal ou, mais consistentemente, em alguns Estados da Federação, devem merecer, igualmente, atenção da Reforma. Diante do compromisso político do Governo com a Nação, de participação e transparência da ação governamental dentro de um regime democrático, conviria refletir seriamente sobre a criação de um canal específico para o exercício desse direito, já que a representação pelos canais políticos tradicionais, 
desgastada e despreparada, não tem assegurado à comunidade a devida expressão dos seus direitos e interesses.

4.5. Finalmente, as relações do Poder Executivo com o Legislativo e o Judiciário passam, necessariamente, por mecanismos administrativos, ainda que o seu conteúdo seja, especialmente no caso do Legislativo, eminentemente político. Os órgãos de assessoramento parlamentar e de relações com o Judiciário são, via de regra, no Brasil, conservadores, formalistas, de certa forma alienados quanto às exigências de uma ação mais pronta e eficaz da Administração. Merecem, portanto, aquelas relações fazer parte da agenda da nova Reforma.

Naturalmente, os mecanismos de coordenação da Reforma, em estreita sintonia com os compromissos do Governo, deverão compor a agenda final do processo de reforma, assegurando sua ampla discussão pelo conjunto dos participantes legitimamente interessados na questão.

\section{Conclusões}

O longo período autoritário pelo qual o País passou acarretou não só aos Governos revolucionários, mas também à própria Administração Pública, um enorme desgaste junto à opinião pública. Coincide com o momento histórico da reconstrução democrática uma grande aspiração social por uma melhor administração da intervenção do Estado em favor dos interesses sociais.

Sente-se a comunidade disposta a um voto de confiança, a participar dessa ingente tarefa de reconstrução ou de, pelo menos, aperfeiçoamento da máquina administrativa.

A verdade é que essa máquina passou por um dramático processo de proletarização. Há meio século ou menos, faziam uso dos serviços públicos segmentos da elite social: as escolas públicas tinham o melhor serviço; os postos de saúde, a melhor atualização contra as doenças endêmicas e a prevenção; os hospitais públicos eram modelares: e assim por diante. Aos poucos, seja pela explosão da demanda das classes menos favorecidas, seja pela progressiva escassez de recursos para uma oferta maior e melhor qualificada, baixaram os níveis de atendimento. A classe média ascendente encontrou nas estruturas privadas, que tiveram seu mercado alargado, melhores serviços. Apenas as classes de renda mais baixa, e os sem renda, continuaram a utilizar as redes tradicionais dos serviços públicos da área social.

Como efeito de causação circular, os padrões administrativos foram descurados. Proletarizados os serviços públicos, na falta de canais de articulação e de pressão 
política, contidos pelo sistema autoritário e repressor, contentaram-se os usuários com a precariedade da prestação do Estado, amedrontados, ainda, pela possibilidade da perda de acesso ao que lhes restou.

Assiste-se, atualmente, a uma reversão dessa tendência. Primeiro porque a classe média baixa foi duramente atingida pela crise econômica e voltou a procurar os serviços públicos; segundo, porque liberalizado o regime ou, pelo menos, a articulação social, não está a população tão passiva quanto permaneceu nesses 20 anos.

Essa pressão irrompe Administração adentro e obriga ao repensar da ação política e programática do Governo. A Administração torna-se uma arena de reivindicações e protestos.

É a pressão por mudança, por reformas, de que falamos no início destas considerações.

A essa participação renovada da sociedade soma-se a abertura para a participação interna dos servidores públicos. Não para a discussão, interesseira e exclusiva, da questão salarial ou de aspectos técnicos dos tradicionais planos de cargos e salários, da carreira, do treinamento, e outras dimensões da administração de pessoal. Para animar essas questões existem as associações, e talvez no futuro, os sindicatos. Tratase de permitir aos servidores questionar os objetivos, as políticas, os programas, a utilização dos recursos dos órgãos e entidades a que pertencem, trata-se de restituirIhes a possibilidade da recuperação do sentido de "servir ao público", de onde lhes vem a denominação genérica. Isto é, reencontrarem eles próprios a cidadania e a responsabilidade que o cargo ou emprego público lhes acarreta.

A Reforma não pode, neste momento histórico, perder qualquer das duas contribuições participativas, para transformar-se na obra exclusiva de especialistas técnicos, com a sanção dos dirigentes políticos.

A seletividade e o ritmo, a estratégia e as táticas de sua concepção e implantação precisam dessa sintonia com a sociedade em geral e com o corpo social da própria Administração.

Partir das ações efetivas, dos programas prioritários que expressam as políticas públicas, base do compromisso político e da legitimidade dos detentores do poder, é certamente uma forma alternativa de iniciar a Reforma que, na pior das hipóteses, será gratificante, ainda que sujeita às dificuldades de uma tentativa pioneira. 


\section{Referências bibliográficas}

DelfiM Netto, Antonio. Planejamento para o desenvolvimento econômico. São Paulo: Pioneira/ EDUSP. 1966. 127p.

Manter o desenvolvimento e reduzir a dependência externa s.l.p. SEPLAN/PR. 44p. Palestra proferida na ESP. 1980.

GARCIA, R. M. Alternativas organizacionais; as redes institucionais de apoio à produção local de alimentos. In. FUNDAP - Fundação do Desenvolvimento Administrativo. Administração Pública Brasileira - 1964/- 84. São Paulo, 1985. p. 55-85 (Documentos de Trabalho, 4).

LOUREIRo PINTO, Aluizio. O Decreto-Lei no 200 como estratégia de modernização institucional. In: FUNDAP - Fundação do Desenvolvimento Administrativo. Administração Pública Brasileira - 1964/84 São Paulo, 1985p. 5-21 (Documentos de Trabalho, 4). 